must fall on local museum curators, just as that of library extension has been borne by public librarians. There can be no question of the willingness of curators to help ; many of them have been doing the work for years, sometimes with the co-operation or at least the sanction of the educational authorities, sometimes in spite of their lethargy, and out of their own slender resources. If the Carnegie Trustees can induce the educational authorities in any one area to co-operate whole-heartedly with the museum curators, an example will speedily be set which the rest of the country will feel bound to follow. It is, however, to be hoped that the benefits will not be confined to schoolchildren, but that the needs and interests of others, especially the adolescent, will be kept prominently in view.

\title{
International Congress of Actuaries.
}

$\mathrm{T}^{\mathrm{H}}$ $\mathrm{E}$ ninth international congress of actuaries was held at Stockholm on June 16-20 and was largely attended by actuaries from all over the world. The arrangements were made by the Swedish Society of Actuaries and the Swedish Association of Assurance, and the presidents for the time being of those bodies (Dr. Phragmén and Mr. Sven Palme) being the joint presidents of the Congress. Several subjects were chosen for discussion and the papers submitted were printed in English, French, or German, at the author's choice, with abstracts in the other languages. Each subject was then introduced by a short speech by a Scandinavian actuary and a general discussion followed.

One of the subjects of most general interest discussed at the Congress was the treatment of sickness and disability in social insurance or in connexion with pensions or life assurance, and it was apparent that the granting of these benefits on invalidity has led to far heavier rates of invalidity than those prevailing prior to the institution of the schemes. This effect is noticeable whether we look at State or private schemes of insurance. Attention had already been directed to the point in England, and most other countries are having to face the same difficulties. It is probably inevitable that, even if definite malingering be excluded, some such result should appear, but it makes the actual expense of such schemes greater than the estimated expense on the basis of older experience acquired in different conditions. The subjects of general scientific rather than professional interest were the statistical evidence available with regard to the influence of tuberculosis on mortality and the application of modern statistical treatment to problems of risk. In connexion with the latter, non-Scandinavian actuaries had the opportunity of considering Lundberg's interesting new theory of risk, and it was satisfactory to find a paper giving a definite warning against the assumption of the normal curve, in connexion with the discussion of deviations in assurance work, when Poisson's law would be a proper assumption.

On the strictly actuarial side, the fair distribution of surplus was discussed by many actuaries in written and verbal communications, while on the practical life assurance side the comparison of 'participating with 'non-participating' assurances and the relative advantages of assurances that merely cover risk, as compared with those that are largely for purposes of saving, evoked a good discussion.

The meetings were held in the new concert hall and the arrangements were excellent. The interpreting was remarkably good; thanks partly to the choice of linguists with a first-class knowledge of the subjects under discussion.

The Congress was graciously received at the Royal Palace for tea by H.M. the King, and the Crown Prince, as Président d'honneur, attended and spoke at the opening meeting. It only remains to record the generous hospitality of our Swedish hosts to the members of the Congress and their wives : it would be hard to imagine greater kindness.

W. P. E.

\section{Rayleigh Collection at the Science Museum.}

$\triangle M O N G$ recent additions to the Science Museum, $\mathrm{A}^{\mathrm{N}}$ South Kensington, is a most interesting collection of apparatus used by the late Lord Rayleigh in the course of his scientific research. On the occasion of the unfortunate fire, last year, at Lord Rayleigh's home at Terling, Essex, a considerable quantity of apparatus was destroyed, but the historical apparatus was fortunately undamaged and the bulk of it has been generously given by the present Lord Rayleigh to the Science Museum, where it should prove a continual source of interest and inspiration to professional and amateurscientific workers alike. It is scarcely necessary to remind readers of NATURE of the extent and importance of the late Lord Rayleigh's contributions to science. During a period of more than fifty years he published no fewer than 446 papers, every one of which made a distinct addition to our knowledge of the subject and was characterised by that lucidity and elegance of expression for which its author was renowned.

On viewing this collection, one is struck very forcibly -as were visitors to the laboratory at Terling-by the extraordinary simplicity of the bulk of the apparatus. The ability to attain results of the highest accuracy and importance by the aid of odd bits of wood, glass tubing, wire, and sealing-wax was undoubtedly bound up with Rayleigh's unerring instinct in discriminating between the essential and the non-essential. It is doubtless true that some branches of modern physical research cannot profitably be pursued without the use of expensive apparatus. At the same time, many workers who are apt to grow despondent after a perusal of the price-lists of the scientific instrument makers should find a tonic in the Rayleigh collection, which also serves as a salutary reminder that the man is more important than his tools.

The present collection is thoroughly representative of the vast field which Lord Rayleigh covered, and is exhibited in six cases, two dealing with acoustics, while the remainder come under the headings of optics, magnetism and electricity, argon, and miscellaneous. It is impossible in a short notice to deal adequately with the whole of the exhibits, but a few representative examples may perhaps be mentioned. The acoustics section includes apparatus used in experiments on reflection and interference and on the intensity of aerial vibrations ; also the apparatus by means of which it was demonstrated that our lateral perception of the direction of a sound depends upon the phase-difference at the two ears. One of the most important exhibits in the optical section is the apparatus used for the determination of the constant of the magnetic rotation of light in carbon disulphide, while there is also a reminder that, so early as the year 1902, Rayleigh made an attempt to detect motion through the æther. Prominent in the electrical section will be found

No. 3167, Vou. 126] 